\title{
End-User Adoption of Bitcoin in South Africa
}

\author{
Raphael Warren Jankeeparsad, Dev Tewari \\ University of Zululand, South Africa \\ jankeeparsadr@unizulu.ac.za, tewarid@unizulu.ac.za
}

\begin{abstract}
Since its introduction in 2008, the value and popularity of Bitcoin have risen exponentially. Despite being 10 years old, the concept of crypto currency is fairly new in South Africa. The increase in the value of Bitcoin, together with extensive media coverage, has led to the creation of a Bitcoin economic system with many South Africans jumping on the Bitcoin bandwagon. This study aims to identify the determinants affecting end-user adoption of Bitcoin in South Africa and to determine the main use of the crypto currency by South Africans. A research model was developed utilising constructs from the technology acceptance model and theory of planned behaviour. The model was then tested empirically by utilising two survey-based questionnaires, one for current users of Bitcoin and one for non-users. For users, perceived usefulness and access to facilitating conditions were the primary determinants influencing their decision to adopt the crypto currency while lack of trust and social influences were the primary reasons non-users chose not to adopt Bitcoin.
\end{abstract}

Keywords: Bitcoin, Crypto currency, South Africa

\section{Introduction}

User acceptance of digital transactions has increased significantly since the introduction of the internet and electronic commerce. The rapidly changing world of technology has introduced many new technologies, one of which is the introduction of crypto currency. Crypto currency is a digital or virtual currency that uses cryptography for security. The defining feature of crypto currency is that it is not issued by any central authority or bank, rendering it theoretically immune to government interference or regulatory bodies (Sontakke \& Ghaisas, 2017). The world's first and most popular crypto currency, Bitcoin, was developed in 2008 by an individual or group known under the pseudonym Satoshi Nakamoto (Whigham, 2017). Originally, the creators of Bitcoin used the currency for Internet-related tasks, like trading Bitcoin for programming assistance. Since then, the use of Bitcoin has expanded and has gained increasing acceptance in broader contexts globally (Rice, 2013). Since its inception, the value of Bitcoin (which is driven by supply and demand) has increased exponentially. In 2010, a single bitcoin traded for USD0.06. Fast forward to December 2017 and the value of Bitcoin peaked at USD19 783 (Zhao, 2017). This unprecedented increase in value together with extensive media coverage has led to the development of an active economic system around Bitcoin. The crypto currency is now being used in online shopping, held as an asset class and traded via online exchanges (Silinskyte, 2014). These factors, together with the fact that there is a limited supply of Bitcoin (21 million coins), has resulted in increased demand for these coins with many end-users purchasing Bitcoin as a speculative instrument. Around the world, Bitcoin is accepted by a wide variety of businesses and retailers. In countries like the USA, Canada and Austria, Bitcoin automatic teller machines can be found which allows individuals to buy and sell Bitcoin for cash (Madeira, 2017).

In December 2017, the first ever Bitcoin futures became available by the Chicago Board Options Exchange increasing its appeal for mainstream traders. Futures are a type of contract where investors agree to buy or sell an asset on a specific future date at a specific price (Pauw, 2017). The trading of Bitcoin futures represents a historical event for Bitcoin because while the price of Bitcoin remains unregulated, Bitcoin futures will be traded on regulated exchanges. This event resulted in the public showing an even greater interest in Bitcoin which caused the price of Bitcoin to hike by $10 \%$ within an hour of the first futures being launched. South African's have shown a great interest in crypto currencies, with South Africa consistently ranking highest worldwide in search interest for "Bitcoin" according to data from Google Trends (McKane, 2018). It is therefore no surprise that Bitcoin transactions are gaining traction in South Africa. Pay fast (one of South Africa's largest online payment processing companies) has introduced Bitcoin as a method of payment. Takealot.com, South Africa's largest online store is also accepting Bitcoin as a payment method using Pay fast (Ngubeni, 2014). South Africans can also now pay traffic fines using Bitcoin via the company Fines4U (Slabbert, 2017). Red \& Yellow, a business school in South Africa, is now accepting Bitcoin as a payment 
method for all their degrees and online courses (Steyn, 2018). Even though this crypto currency has taken these massive leaps forward, Bitcoin (and crypto currency in general) is still a relatively new concept for South Africans.

Due to the anonymity of Bitcoin transactions, it is difficult to estimate how many South Africans own or have transacted with the crypto currency. As of August 2017, data reveals that the market capitalisation of South African Bitcoin holdings were just over R1 billion compared to a global market capitalisation of over USD70 billion (Naidoo, 2017). Bid or Buy, South Africa's biggest online marketplace, reported that transactions using Bitcoin represent only a fraction of the sites overall revenue (Kelso, 2017). As the crypto currency market is relatively new, it is not clear what the requirements for successful Bitcoin adoption in South Africa should be. Compared to other countries such as the USA and Japan which accounts for $29 \%$ and $52 \%$ of the market share of the global Bitcoin exchange market respectively (Young, 2017), the adoption of Bitcoin in South Africa is significantly lower. Despite the unprecedented growth of Bitcoin and its growing uses in South Africa, to the researcher's knowledge, no research has been conducted to determine the Bitcoin adoption factors by enduser individuals in South Africa. Often described as a disruptive technology, many researchers believe that Bitcoin has the potential to change the landscape of financial services and usher in a new era of banking and transacting while creating more dilemmas for regulatory authorities and policymakers (Trautman, 2016). In order for Bitcoin to gain increased acceptance amongst all economic participants, it is important to identify and understand the Bitcoin adoption factors. The research problem that this study therefore aims to address is the identification of the determinants affecting end-user adoption of Bitcoin in South Africa. Factors that influence adoption need to be determined in order to be able to give a better perspective of the future of Bitcoin in South Africa. Therefore, the research objectives of this study are: To identify possible determinants of Bitcoin adoption amongst end-user individuals in South Africa; To identify possible barriers that prevent potential end-user individuals from adopting Bitcoin in South Africa; To determine how actual end-users utilise Bitcoin in South Africa.

Whilst research has been conducted on the adoption of Bitcoin in other countries including the USA (Schuh \& Shy, 2015), Netherlands (Silinskyte, 2014) and Indonesia (Gunawan \& Novendra, 2017), to the researcher's knowledge, a study of this nature has not been conducted in South Africa. This study therefore posits that by determining and understanding adoption factors, researchers and the various businesses who plan to or are currently transacting in Bitcoin, can get a better understanding of the reasons end-users choose to adopt Bitcoin or not. From a practical point of view, the results of this study could be used in a company's strategy (including trading exchanges) for Bitcoin adoption in order to gain knowledge and an understanding of actual users and non-users of Bitcoin. Currently, Bitcoin is being utilised as a speculative instrument for profit making, an investment in the crypto asset class and as a form of currency to make purchases online. In South Africa, legislation has not been able to keep up with crypto currency phenomenon resulting in tax losses for the South African Revenue Services (SARS) as there is no way to trace profits made by South Africans due to the unregulated trading of crypto currencies. SARS relies on the honesty of taxpayers as the onus is on the taxpayer to declare any profits made from trading of crypto currencies. This study will provide insight as to what percentage of users of Bitcoin are currently utilising the crypto currency for profit-making motives and what percentage are using Bitcoin to effect payments in online transactions. In an effort to improving their strategic planning for the identification of crypto currency profits, SARS can therefore benefit from the results of this study and use it to extend and enhance their knowledge of how Bitcoin is being used in South Africa.

\section{Theoretical Background}

The Introduction and Rise of Bitcoin: Over the past decade, virtual currencies have made great leaps. Bitcoin, which was developed in 2008 by a person or group using the pseudonym Santoshi Nakomoto, was the first virtual currency which simultaneously serves as a medium of exchange (by making use of a peer-topeer payment system) as well as a store of value (in the form of a decentralised virtual currency) (Bohr \& Bashir, 2014). Bitcoin is described as "an electronic payment system based on cryptographic proof instead of trust, allowing any two willing parties to transact directly with each other without the need for a trusted third party" (Nakamoto, 2008). Essentially, when users complete a transaction using Bitcoin, the transaction is logged digitally. This transaction log is called the "blockchain" and records every single transaction and the ownership of every single Bitcoin in circulation (Kumar, 2013). Through a process called "mining", all 
transactions are verified through the cryptographic proof in the peer-to-peer network (Bohr \& Bashir, 2014). In return for their services, miners are paid fees by the merchants for each transaction and are also rewarded with Bitcoin (Tschorsch \& Scheuermann, 2016). As there is no third party involvement, transaction fees are low. A major downside is that once a transaction has been entered into, it cannot be reversed (Silinskyte, 2014).

Bitcoin is decentralised and unregulated meaning it is not issued by any central authority (e.g. a government or bank) (Bamert, Decker, Elsen, Wattenhofer, \& Welten, 2013). In addition to this, users of Bitcoin are anonymous as they are not identified by their actual identities but are only identified by public keys (Reid \& Harrigan, 2013). This characteristic has had a negative impact on the crypto currency as it became popular as a medium of exchange for illicit goods including banned substances and illegal weapons (Gunawan \& Novendra, 2017). Being a virtual currency, Bitcoin is susceptible to digital security threats. In 2014, Mt GOX, the largest Bitcoin exchange at that time, was a victim of a cyber-attack resulting in 450 million dollars' worth of Bitcoin being stolen (Li, Jiang, Chen, Luo, \& Wen, 2017). Due to the fact that Bitcoin is unregulated, as of December 2017, it is banned in countries such as Bolivia, Ecuador and Bangladesh. In addition to this, China has also announced the closure of crypto currency exchanges (Williams, 2017). Even though there have been setbacks, the value of 1 Bitcoin has skyrocketed since its introduction. The price of Bitcoin is measured against fiat currencies and is based on demand and supply. Unlike fiat currencies, there is no official international Bitcoin price and its price varies across the various exchanges internationally (Ram, Maroun, \& Garnett, 2016).

The price of Bitcoin is extremely volatile. Bohr \& Bashir (2014) suggest that this could be due to the fact that speculators got involved with Bitcoin as an investment rather than treating it as a practical traditional currency. As a result of its significant growth over a relatively short period of time and extensive media coverage, South Africans have taken a keen interest in Bitcoin. Luno, one of the registered Bitcoin exchanges in South Africa, reports that in November 2017, out of its 2000 Bitcoin transactions per day, over 750 Bitcoin transactions took place in South Africa (MyBroadband, 2017). The reasons why South Africans purchase Bitcoin vary a survey conducted by Luno in 2017 revealed that $39 \%$ of the respondents purchase Bitcoin as an investment while $13 \%$ and $14 \%$ transact with the currency for payments and trading/speculation respectively (Edmunds, 2017). Even though the South African Reserve Bank does not recognise Bitcoin as legal tender (Raviv, 2016), many retailers and merchants in South Africa have started accepting Bitcoin as a payment method. Despite the continuous growth and exposure of Bitcoin in South Africa, not much research has been done to identify the factors that promote or hinder the adoption of Bitcoin amongst end-users and non-users of the crypto currency. Previous research into Bitcoin adoption in other countries suggests that being a form of technology (by virtue of being a digital currency), technology acceptance and its various theoretical models provide an understanding of the factors that contribute to the adoption of Bitcoin.

Development of the Research Model: Like many other technological innovations before it (including the internet, electronic mail, internet banking, etc.), Bitcoin, a digital currency, is an information technology (hereafter IT) innovation. Extensive research into technology acceptance has resulted in the development of several theoretical models which have been tested empirically. In the development of these models, various factors have been considered including information systems, psychology and sociology (Venkatesh, Morris, Davis, \& Davis , 2003). A significant aspect in the literature on technology acceptance has been the effect of intention-based models which use behavioural intention (hereafter $\mathrm{BI}$ ) to predict actual usage of the technology being examined (Chau \& Hu, 2001). The objective of these models is to determine the various factors that can influence an individual's behavioural intention to adopt and consequentially use a specific technology. Considerable empirical research has reported a significant causal link between intention and actual behaviour (Chau \& Hu, 2001). These studies report that an individual's intention to use a specific technology is positively correlated with their actual use of the technology (Sheppard, Hartwick, \& Warshaw, 1988). In a scenario where the technology being investigated is currently available for use (like Bitcoin that is available in South Africa), intentions are the preferred predictor of actual usage (Szajna, 1996). Based on this, an intentions-based model was considered the most appropriate for this study as users of Bitcoin and nonusers are being investigated. Previous studies on Bitcoin adoption that used an intentions-based model concluded that there is a significant positive correlation between intention to use Bitcoin and its actual usage (Silinskyte, 2014; Gunawan \& Novendra, 2017). One of the earliest and most widely used acceptance models 
is the Technology Acceptance Model (hereafter TAM) which was developed through a doctoral dissertation by Davis in 1986. In this model, actual usage of a system or technology is determined by BI, while BI is viewed as being jointly determined by the perceived ease of use (hereafter PEOU) and perceived usefulness (hereafter PU) of the system (Davis, 1989) One of the biggest limitations of TAM was that it focused on basic information systems usage and hence has limitations in being applied beyond the workplace (Fu, Farn, \& Chao, 2006).

This has led to various modifications of the original model being successfully applied to a variety of nonorganisational settings including predicting usage for online shopping (Gefen, Karahanna, \& Straub, 2003), wireless internet (Venkatesh \& Ramesh, 2006) and internet banking (Cheng, Lam, \& Yeung, 2006).

Over the years following the development of TAM, various other intentions based models were developed including the Theory of Planned Behaviour (hereafter TPB) by Ajzen in 1991. This model posits that BI is determined jointly by an individual's attitude, subjective norms and perceived behavioural control (an individual's perceived ability to operate a system as well as having the necessary resources to do so). Significant research has been conducted in many fields on the accuracy of TPB in predicting intention including IT adoption in the work environment (Venkatesh, Morris, Davis, \& Davis , 2003), acceptance of eGovernment services (Hung, Chang, \& Yu, 2006) and adoption of virtual banking (Liao, Shao, Wang, \& Chen, 1999). These studies have found that ТРB predicts behavioural intention accurately. In developing an intentions-based model for this study, the constructs of both the aforementioned models were used. These specific models were chosen for their parsimony and explanatory power in various scenarios. In addition to this, neither of the two has been found to be a superior predictor of intention than the other. The following modifications have been made to the original models in the development of a research model for this study.

The "attitude" construct from the original TPB has been decomposed using PU and PEOU from TAM. This was proposed by Mathieson in the development of his model "The Decomposed Theory of Planned Behaviour" in 1991. Many empirical studies have considered the role that "attitude" has the intention to use information technology systems. Venkatesh and Davis (2000) removed the "attitude" construct from their model because attitude did not appear to fully mediate the effect of PU and PEOU on BI as was initially believed. A new construct in the form of "trust" has been added to this research model as a direct determinant of intention to use. Bitcoin is a virtual currency and hence trust of the Bitcoin network and its' intermediaries is required by users and potential users of the crypto currency. Whilst other studies on Bitcoin adoption utilise models such as the Unified Theory of Acceptance and Use of Technology model (Silinskyte (2014) and Novendra \& Gunawan (2017)) or the Diffusion of Innovations theory (Connolly \& Kick, 2015), these models were not considered appropriate for this study as these are generally used to examine adopters of a certain technology. This study aims to identify the determinants of Bitcoin adoption by both users and non-users.

\section{Figure 1: Research Model}

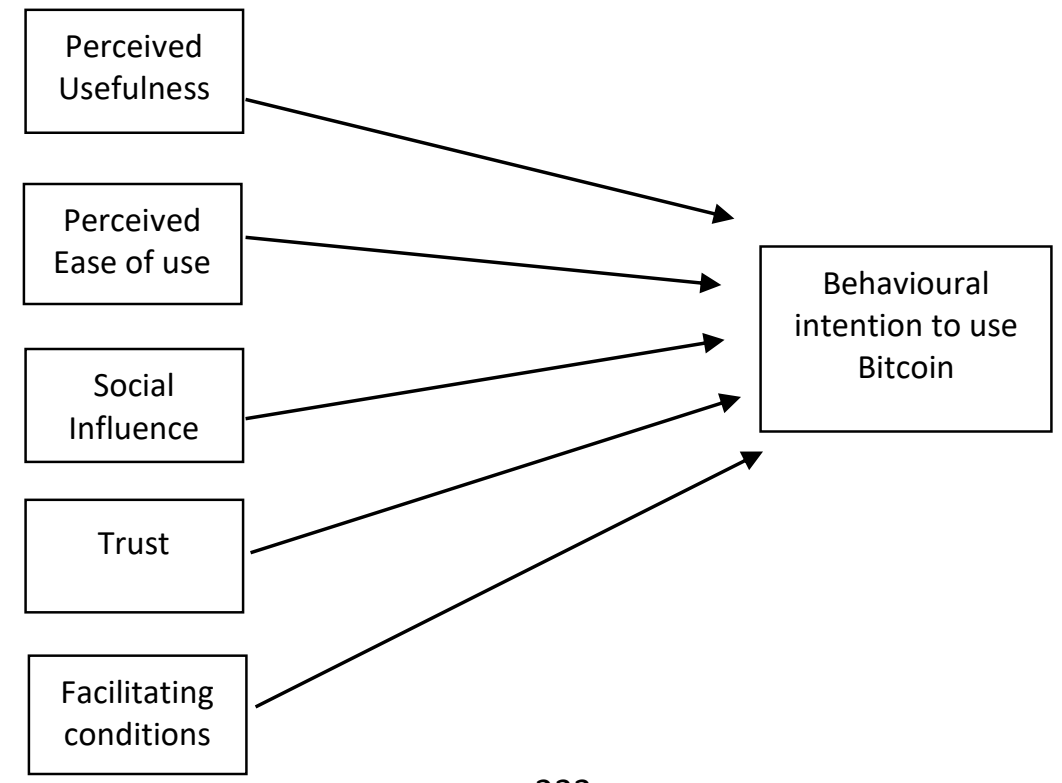




\section{Constructs and Development of the Hypotheses}

Perceived Usefulness (PU): PU refers to the extent to which a person perceives that using a particular technology would improve his or her performance (Davis, 1989). Chau \& Hu (2001) concluded empirically that PU is the most significant construct for the adoption of technology. In the Bitcoin context, a user will most likely adopt Bitcoin if they find the technology useful as a payment method, speculative investment or asset class. In their study on the acceptance of Bitcoin in Indonesia, Novendra \& Gunawan (2017) report that PU has a positive and significant effect on BI of using Bitcoin.

H1: Perceived Usefulness will have a positive influence on behavioural intention to use Bitcoin.

00Perceived Ease of Use (PEOU): PEOU refers to the extent to which an individual perceives that using a particular information system will be free of effort (Davis, 1989). In the Bitcoin context, an end user's positive or negative feelings concerning the Bitcoin system, in particular their perceptions on the level of difficulty associated with the use of the technology will have an impact on their decision to use or not to use Bitcoin. Silinskyte (2014) and Folkinshteyn \& Lennon (2017) determined empirically in their respective studies that ease of use has a positive influence on an individual's BI to use Bitcoin. This was also concluded by Abramova \& Bohme (2016) in a study on the determinants of Bitcoin use in Europe thus the hypothesis being tested.

H2: Perceived Ease of Use will have a positive influence on behavioural intention to use Bitcoin.

Social Influence (SI): Referred to in other studies on technology acceptance as subjective or social norms, social influence (SI) is defined as an individual's perception of significant others' opinions on whether or not he or she should perform a particular behaviour or use a particular system (Chau \& $\mathrm{Hu}, 2001$ ). A potential Bitcoin user will be more likely to adopt its usage if those important to him/her (e.g. supervisors, mentors, friends, family etc.) are currently using Bitcoin or advocate for it. The hypothesis being tested is:

H3: Social influence will have a positive influence on behavioural intention to use Bitcoin.

Trust: Trust in the Bitcoin context refers to users trust in Bitcoin technology experienced before, during, and after engaging in online transactions (Sas \& Khairuddin, 2015). In order for end- users to ultimately trust the Bitcoin technology, they must be satisfied that their Bitcoin account is secure and that the exchanges they are trading from have implemented the necessary safeguards to prevent any breach in security. Silinskyte (2014) reports that out of the 13 respondents who did not use Bitcoin in his study, 4 cited "no trust" as the primary reason why. Presthus \& O'Malley (2017) found that one of the main reason non-users of Bitcoin have not adopted the technology is due to security concerns. The hypothesis being tested is:

H4: Trust will have a positive influence on behavioural intention to use Bitcoin.

Facilitating Conditions (FC): In the Bitcoin context, facilitating conditions (hereafter FC) refers to the degree to which a user or potential user believes that a technical infrastructure exists to support the use of the crypto currency (Venkatesh, et al., 2003). This infrastructure includes the necessary resources to assist with learning about Bitcoin and compatibility with existing technologies that have been adopted by the individual. FC also includes the technology and facilities to access the Bitcoin network and transact with the crypto currency. Gunawan \& Novendra (2017) and Silinskyte (2014) report that there is a positive relation between FC and use of Bitcoin. The hypothesis being tested is:

H5: Facilitating conditions will have a positive influence on behavioural intention to use Bitcoin.

\section{Research Design}

This is an empirical study in which new data was collected relating to the research objectives identified. The inquiry strategy that was used to obtain the data necessary for this study is that of survey research. In general, a survey involves the collection of information from individuals about themselves or a specific phenomenon being investigated (Forza, 2002). Survey research entails obtaining data about the attitudes and opinions of a sample of individuals, with the objective of extrapolating their responses to that of a greater 
population (Leedy \& Ormrod, 2010). For this study, which seeks to determine the factors that influence the adoption of Bitcoin in South Africa and uses a theoretical model to test hypotheses developed, a quantitative, survey-based inquiry strategy was considered the most appropriate. A study of this nature involves the willingness of individuals to voluntarily provide responses to questions that test the hypotheses developed. Due to many factors that affect an individual's willingness to assist, such as time constraints, general attitude and interest in the problem being researched, a quantitative survey-based research strategy was utilised to obtain data and this was considered the most appropriate method. This choice is supported by previous empirical studies in other countries that have also used quantitative survey approaches to determine factors that influence or deter the use and adoption of crypto currency.

Sampling: The target population consisted of users and non-users of Bitcoin located in South Africa. Representative sampling poses a challenge to analyse Bitcoin usage as the system is designed to be anonymous, decentralised and voluntary to use. Thus, there is no central database to identify Bitcoin users and non-users and studies on Bitcoin adoption have concluded that Bitcoin users are hard to reach population (Henry, Huynh, \& Nicholls, 2017). Acknowledging these challenges, the surveys were made available via online South African Bitcoin forums and Bitcoin communities on social media websites where individuals could voluntarily choose to participate or not. The forum administrators were contacted for permission to administer the questionnaire after ethical clearance was granted. It is important to note that these forums and communities consist of individuals who own or have owned Bitcoin before as well as potential users who have never owned Bitcoin but are interested in trading in or owning Bitcoin. These platforms were considered the most appropriate as the potential respondents would have, at the very least, a basic understanding of Bitcoin and its various uses. Links to the questionnaires were posted by the researcher and the administrators of the forums encouraged members to respond.

Data Collection: Data for this study was collected through two structured questionnaires, one for users of Bitcoin and one for non-users. Regarding the construction of the questionnaire, the questions used to observe and test the constructs of each investigated variable were designed from relevant previous studies on enduser adoption of Bitcoin and technology in general including online banking and electronic filing of tax returns. These questions were then reconstructed to suit the objectives of this study and test the hypotheses constructed. The first part of the questionnaire required the respondent to enter demographic data including gender, age and education profile. Respondents were also required to indicate if they are South African residents as this study is limited to users and non-users from South Africa. Part 2 of the questionnaire tests each construct from the research model. A 5 point Likert-type scale was utilised with $1=$ "strongly disagree" and 5 = "strongly agree". Part 1 and Part 2 of the questionnaires were identical for users and non-users. Users were asked one additional question relating to how they currently utilise Bitcoin. The data collected was then coded and analysed using SPSS for Windows.

\section{Analyses of Results}

Demographic characteristics of the respondents appear in table 1 . This analysis revealed that the majority of Bitcoin users are male, representing $78 \%$ of the total sample. In addition to this, users of Bitcoin are generally younger than non-users with $86 \%$ of the respondents aged 40 and below as opposed to only $52 \%$ of the sample of non-users. These findings are consistent with the studies by Novendra \& Gunawan (2017), Schuh \& Shy (2015) and Bohr and Bashir (2014) who concluded that it is expected that the use of Bitcoin will be more significant for males, particularly younger males. The education profiles of both groups were fairly similar thereby suggesting that the decision to adopt Bitcoin is not dependent on the education profile of the individuals in South Africa.

Table 1: Sample Demographics and Education Profile

\begin{tabular}{lllll}
\hline & Count & Percentage & Count & Percentage \\
\hline Gender & & & & \\
Male & 95 & $78 \%$ & 75 & $63 \%$ \\
Female & 27 & $22 \%$ & 44 & $37 \%$ \\
\hline
\end{tabular}




\begin{tabular}{lllll}
\hline Age (years) & & & & \\
$18-25$ & 16 & $13,1 \%$ & 15 & $12,6 \%$ \\
$26-40$ & 70 & $57,4 \%$ & 47 & $39,5 \%$ \\
$41-50$ & 21 & $17,2 \%$ & 28 & $23,5 \%$ \\
$>50$ & 15 & $12,3 \%$ & 29 & $24,4 \%$ \\
& & & & \\
Highest Education & & - & 1 & $0,8 \%$ \\
$\quad$ Primary & 9 & $7,4 \%$ & 13 & $10,9 \%$ \\
Secondary & 113 & $92,6 \%$ & 105 & $88,2 \%$ \\
Tertiary & & & & \\
\hline
\end{tabular}

Source: Authors analysis

The first test carried out on the data was the reliability test on the research instruments using Cornbrash's alpha which is a measure of internal consistency. A reliability coefficient of 0.70 and above indicates interitem consistency. The Cornbrash alpha of the questionnaire for users was 0.869 and for non-users was 0.734 suggesting that the items have relatively high internal consistency. Frequency tests were then conducted on each group, the results of which are illustrated in tables 2 and 3.

Table 2: Frequency Tests for Bitcoin Users

\begin{tabular}{llll}
\hline & Mean & Std. Dev. & Range \\
\hline PU1 & 4,25 &, 858 & 4,00 \\
PU2 & 3,23 &, 739 & 4,00 \\
PU3 & 3,56 &, 842 & 4,00 \\
PEOU1 & 4,14 &, 878 & 4,00 \\
PEOU2 & 4,49 &, 730 & 3,00 \\
PEOU3 & 4,01 &, 890 & 3,00 \\
SI1 & 3,59 &, 905 & 4,00 \\
SI2 & 3,71 &, 698 & 3,00 \\
SI3 & 2,82 &, 976 & 4,00 \\
T1 & 3,93 &, 757 & 3,00 \\
T2 & 3,96 &, 726 & 4,00 \\
FC1 & 3,95 &, 527 & 3,00 \\
FC2 & 4,00 &, 692 & 4,00 \\
FC3 & 4,31 &, 813 & 3,00 \\
FC4 & 4,18 &, 890 & 3,00 \\
FC5 & 3,84 &, 589 & 3,00 \\
BI & 4,51 &, 815 & 4,00 \\
\hline Sour & & & \\
\hline
\end{tabular}

Source: Authors analysis

Table 3: Frequency Tests for Non-Users

\begin{tabular}{llll}
\hline & Mean & Std. Dev. & Range \\
\hline PU1 & 3,94 & 1,048 & 4,00 \\
PU2 & 2,23 &, 899 & 4,00 \\
PU3 & 2,35 &, 888 & 4,00 \\
PEOU1 & 2,92 &, 749 & 4,00 \\
PEOU2 & 2,78 &, 678 & 3,00 \\
PEOU3 & 2,68 &, 801 & 4,00 \\
SI1 & 2,12 & 1,062 & 3,00 \\
SI2 & 2,62 &, 982 & 4,00 \\
SI3 & 2,48 &, 822 & 4,00 \\
T1 & 1,78 &, 912 & 3,00 \\
T2 & 1,87 &, 987 & 4,00 \\
FC1 & 3,10 &, 710 & 4,00 \\
FC2 & 2,30 & 1,093 & 4,00 \\
\hline
\end{tabular}




\begin{tabular}{lccc}
\multicolumn{5}{c}{$\begin{array}{l}\text { Journal of Economics and Behavioral Studies (ISSN: 2220-6140) } \\
\text { Vol. 10, No. 5, pp. 230-243, October 2018 }\end{array}$} \\
\hline \hline FC3 & \multicolumn{4}{c}{} \\
FC4 & 3,12 &, 916 & 3,00 \\
FC5 & 2,56 &, 829 & 3,00 \\
BI & 3,36 &, 711 & 3,00 \\
\hline Sou & 1,98 &, 911 & 3,00 \\
\hline
\end{tabular}

Source: Authors analysis

Table 4: Pearson's Correlation for Users and Non-Users of Bitcoin

\begin{tabular}{|c|c|c|c|}
\hline & & $\begin{array}{l}\text { Behavioural Intention } \\
\text { for Users of Bitcoin }\end{array}$ & $\begin{array}{l}\text { Behavioural Intention } \\
\text { for Non- users of Bitcoin }\end{array}$ \\
\hline \multirow{2}{*}{ PU1 } & Pearson Correlation & $.708^{* *}$ & $-.338^{* *}$ \\
\hline & $\mathrm{p}$-value & 000 & 000 \\
\hline \multirow{2}{*}{ PU2 } & Pearson Correlation & $.288^{* *}$ & $.243^{* *}$ \\
\hline & p-value & 001 & ,008 \\
\hline \multirow{2}{*}{ PU3 } & Pearson Correlation & $.413^{* *}$ & $.332^{* *}$ \\
\hline & p-value & 000 & 000 \\
\hline \multirow{2}{*}{ PEOU1 } & Pearson Correlation & $.389^{* *}$ & ,122 \\
\hline & p-value &, 000 & 186 \\
\hline \multirow{2}{*}{ PEOU2 } & Pearson Correlation & $.458^{* *}$ & ,035 \\
\hline & $\mathrm{p}$-value &, 000 & ,704 \\
\hline \multirow{2}{*}{ PEOU3 } & Pearson Correlation & $.409^{* *}$ & ,167 \\
\hline & p-value & 000 & 070 \\
\hline \multirow{2}{*}{ SI1 } & Pearson Correlation & $.317^{* *}$ & $.449^{* *}$ \\
\hline & $\mathrm{p}$-value & ,000 & ,000 \\
\hline \multirow{2}{*}{ SI2 } & Pearson Correlation & $.233^{* *}$ & $.551^{* *}$ \\
\hline & p-value & ,010 & ,000 \\
\hline \multirow{2}{*}{ SI3 } & Pearson Correlation & ,009 & $.294 * *$ \\
\hline & p-value & 924 & 001 \\
\hline \multirow{2}{*}{$\mathrm{T} 1$} & Pearson Correlation & $.317^{* *}$ & $.536^{* *}$ \\
\hline & p-value & ,000 & ,000 \\
\hline \multirow{2}{*}{$\mathrm{T} 2$} & Pearson Correlation & $.233^{* *}$ & $.468^{* *}$ \\
\hline & $\mathrm{p}$-value &, 010 & ,000 \\
\hline \multirow{2}{*}{ FC1 } & Pearson Correlation & $.348^{* *}$ & ,173 \\
\hline & $\mathrm{p}$-value & 000 &, 060 \\
\hline \multirow{2}{*}{ FC2 } & Pearson Correlation & $.307^{* *}$ & $.447^{* *}$ \\
\hline & p-value & ,001 & ,000 \\
\hline \multirow{2}{*}{ FC3 } & Pearson Correlation & $.503^{* *}$ & ,033 \\
\hline & p-value & ,000 & ,722 \\
\hline \multirow{2}{*}{ FC4 } & Pearson Correlation & $.496^{* *}$ & 102 \\
\hline & p-value & ,000 & ,268 \\
\hline \multirow{2}{*}{ FC5 } & Pearson Correlation & $.306^{* *}$ &,- 030 \\
\hline & $\mathrm{p}$-value & 001 & ,750 \\
\hline
\end{tabular}

** Correlation is significant at the 0.01 level

Source: Authors analysis 
Thereafter, Pearson's correlations were conducted on the data to determine the strength of the correlation between PU, PEOU, SI, Trust and FC on BI. A Pearson correlation returns a number between -1 and 1 that indicates the extent to which two variables are linearly related. If this correlation coefficient returns a value of 1 , this indicates total positive correlation, 0 is no correlation, and -1 indicates a negative correlation. The Pearson correlation results appear in table 4. In order to verify the Pearson's correlation, a regression analysis was performed on the data, the results of which are illustrated in table 5 and table 6 .

Analysis of Users of Bitcoin: The results of the Pearson's correlation in Table 4 illustrate that there is a significant correlation between the constructs and behavioural intention to use Bitcoin. The regression analysis results on table 5 support this with all constructs having a significant positive relationship with behavioural intention to use Bitcoin thus confirming each of the hypotheses examined. The questionnaires were available for respondents from February 2018 to April 2018 and the survey was completed by 122 users of Bitcoin and 119 non-users. Other studies examining Bitcoin adoption and usage have used relatively small samples. Silinskyte (2014) had a total of 111 respondents in his study on Bitcoin usage in Europe while Gunawan and Novendren (2017) managed to sample a total of 49 respondents in their study on Bitcoin in Indonesia. Based on this, the researchers considered the number of responses received appropriate considering the nature of the topic being researched and its aforementioned challenges. The results of the analysis revealed that Bitcoin users have a strong intention to continue using the crypto currency. A mean of 4.51 was returned for behavioural intention (BI), as illustrated in table 2, indicating that current users of Bitcoin intend to continue using Bitcoin. Thereafter, the T-test was used to compare the results of each construct between the users and non-users of Bitcoin. Probability values (p) of $<.0001$ indicates that both groups of respondents differ significantly on a specific construct.

The results from the T-test returned probability values of $<.0001$ for all constructs examined indicating that the two groups differ significantly in their opinions regarding Bitcoin adoption. The analysis revealed that $66 \%$ of the respondents indicated that their main use of Bitcoin is to use it as an investment in the crypto asset class while the remaining $34 \%$ use Bitcoin as a speculative instrument as illustrated in figure 2 . No respondent indicated that they use Bitcoin as a payment method even though it was initially developed and designed to be used as a payment instrument that would attract little or no transaction costs (Schuh \& Shy, 2015). It can thus be concluded that South African end-users currently do not view decentralisation, the core principle of blockchain technology, as the primary reason for adoption. The results indicate that currently, financial gains and profit-making are the main reasons South African's utilise Bitcoin. Perceived usefulness was a strong determinant of behavioural intention to use Bitcoin. This finding is consistent with the studies by (Silinskyte, 2014) and (Gunawan \& Novendra, 2017). The main reason that end-users adopt Bitcoin is due to the fact that they find it a useful and profitable investment and plan to continue investing in the crypto asset class. With regard to perceived ease of use, users of Bitcoin indicated that they have no difficulty in transacting with Bitcoin and believe that they are skilful in using, purchasing and selling Bitcoin. While social influence is a significant determinant of $\mathrm{BI}$, compared to PU and PEOU, the regression analysis indicated that SI is the smallest predictor $(5,5 \%)$ of behavioural intention.

Users of Bitcoin trust the Bitcoin network and are confident that the necessary safeguards have been implemented to protect the Bitcoins in circulation. 75 percent of the respondents here indicated that whilst they trust the Bitcoin network, they are afraid of the potential hackers and cyber breaches that could destabilise the integrity of the Bitcoin network which has proved to reduce the value of Bitcoin. Finally, facilitating conditions has a significant effect on BI of using Bitcoin. The results indicate that Bitcoin is compatible with the technology the respondents use in their day to day activities and users are confident that they will be able to get assistance with any Bitcoin-related problem or issue that may arise. This assistance may be in the form of Bitcoin online forums and communities. The findings are consistent with those of Gunawan \& Novendra (2017) and Silinskyte (2014) who report that there is a positive relation between FC and use of Bitcoin. Despite the rising transactions fees associated with Bitcoin, $85 \%$ of the respondents indicated that these costs do not inhibit their use of the crypto-currency. This indicates that users are happy with the value of their investment and returns from Bitcoin and the rising costs associated with Bitcoin are not significant enough to warrant outright non-use of Bitcoin. 
Table 5: Results of Regression Analysis for Users of Bitcoin

\begin{tabular}{lllll}
\multicolumn{2}{l}{ Regression Analysis for Users } & \multicolumn{2}{l}{ Coefficients } \\
Construct & R Square & $\begin{array}{l}\text { Adjusted } \\
\text { Square }\end{array}$ & $\mathrm{R}$ & $\begin{array}{l}\text { Std. Error of } \\
\text { Estimate }\end{array}$ \\
PU &, 370 &, 365 &, 64972 & $\begin{array}{l}\text { Standardised Coefficients } \\
\text { Beta }\end{array}$ \\
PEOU &, 241 &, 235 &, 71337 & .609 \\
SI &, 062 &, 055 &, 79288 & .491 \\
Trust &, 282 &, 276 &, 69375 & .250 \\
FC &, 318 &, 312 &, 67642 & .531 \\
\hline
\end{tabular}

(Source: Authors analysis)

Figure 2: Reasons for Adopting Bitcoin by Users

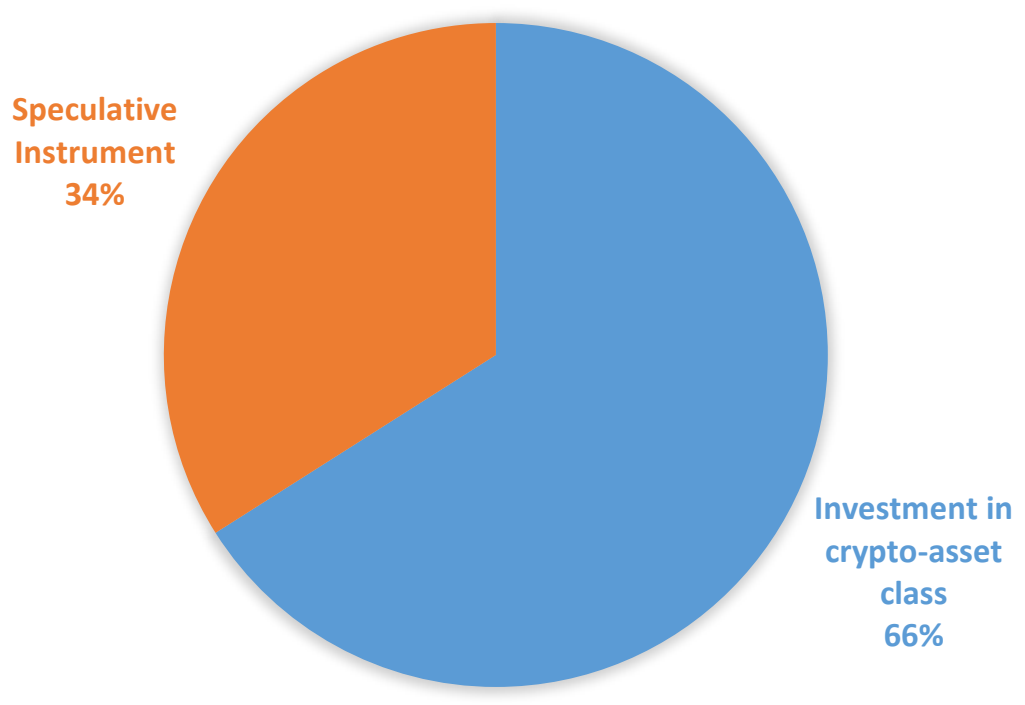

(Source: Authors analysis)

Table 6: Results of Regression Analysis for Non-Users of Bitcoin

\begin{tabular}{|c|c|c|c|c|c|c|}
\hline \multicolumn{5}{|c|}{ Regression Analysis for Non-Users } & \multicolumn{2}{|l|}{ Coefficients } \\
\hline Model & R Square & $\begin{array}{l}\text { Adjusted } \\
\text { Square }\end{array}$ & $\mathrm{R}$ & $\begin{array}{l}\text { Std. Error of the } \\
\text { Estimate }\end{array}$ & $\begin{array}{l}\text { Standardised } \\
\text { Beta }\end{array}$ & Coefficients \\
\hline PU & 013 & 005 & & ,90894 & .115 & \\
\hline PEOU & 020 & ,012 & & ,90571 & .143 & \\
\hline SI & ,292 & ,286 & & ,76992 & .540 & \\
\hline Trust & ,269 & ,263 & & ,78224 & .519 & \\
\hline FC & ,088 & ,080 & & ,87403 & .296 & \\
\hline
\end{tabular}

(Source: Authors analysis) 
Figure 3: Analysis of Constructs - Users VS Non-Users

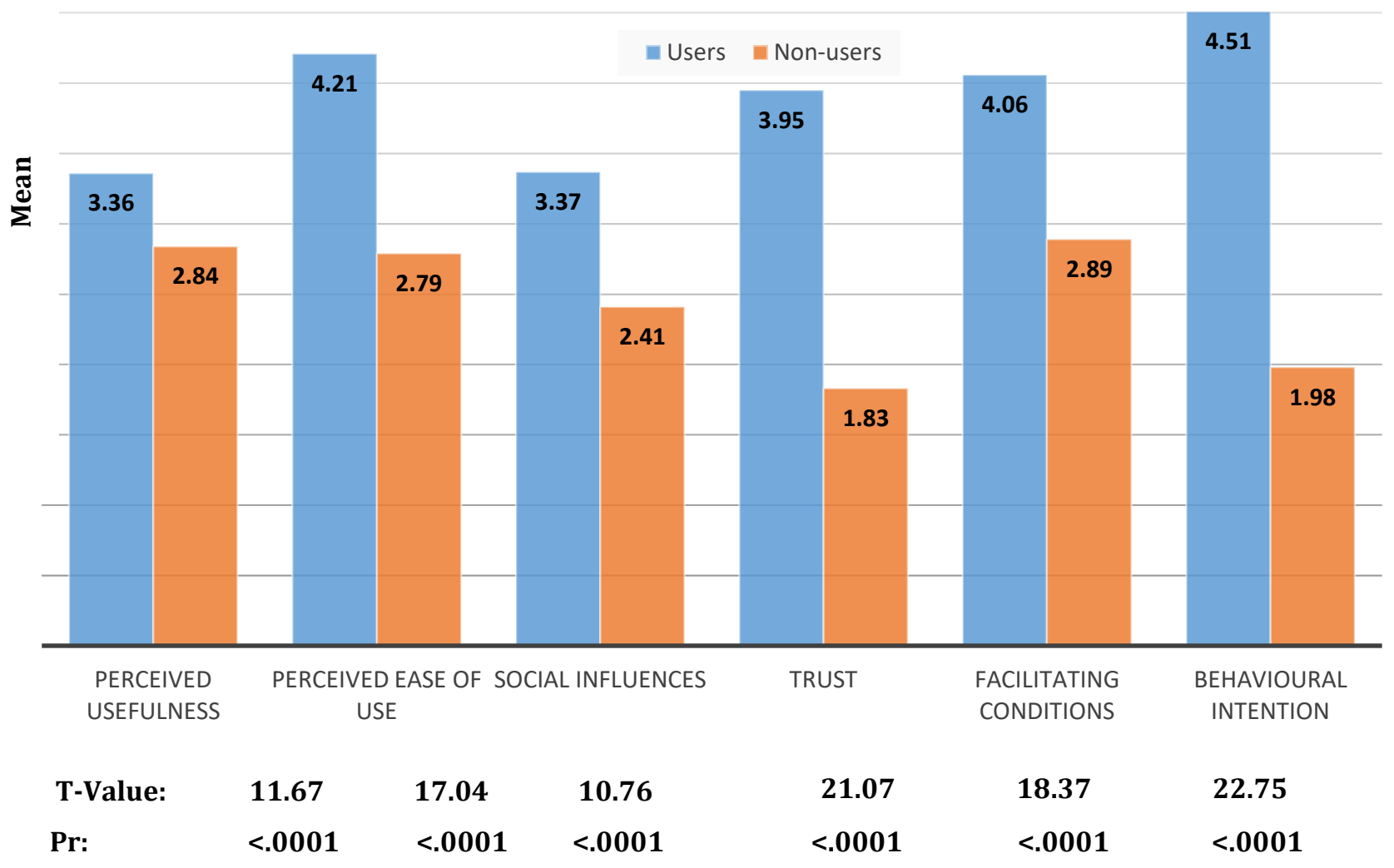

Source: Authors analysis

Analysis of Non-Users of Bitcoin: The results of the analysis revealed that non-users do not intend to utilise the crypto currency in the next 12 months. This is evidenced by a mean of 1.98 being returned for behavioural intention, as illustrated in table 3. The main reason these respondents do not use or plan on using Bitcoin is due to lack of trust around Bitcoin and its various intermediaries in the ecosystem. The results indicate that these individuals do not believe that the necessary security measures have been put into place to protect the integrity of the Bitcoin in circulation and perceive the risk of using or owning Bitcoin as significant. This finding correlates with other studies on Bitcoin adoption by Abramova \& Bohme (2016), Folkinshteyn \& Lennon (2017) and Presthus \& O'Malley (2017). Social influences have a material effect on non-user's future intentions with regard to Bitcoin usage. Individuals with family, friends and influences who encourage the use of Bitcoin or investment in Bitcoin are more likely to utilise the crypto currency than those who do not. The results for this group revealed that their respective influences did not encourage the use of Bitcoin, thereby directly influencing their decision to avoid the crypto currency.

The respondents indicated that they perceive little or no usefulness for Bitcoin. This indicates that non-users agree that Bitcoin will not be useful to them as a payment method, investment or speculative instrument. This finding is consistent with the conclusions by Presthus \& O'Malley (2017) where non-users questioned the benefits of using Bitcoin. Likewise, these respondents do not believe that transacting with the crypto currency will be easy for them. Lastly, the lack of facilitating conditions proved to have a negative impact on BI to use Bitcoin with $67 \%$ of the respondents indicating that the resources required using or owning Bitcoin are not available to them. Only $12 \%$ of these respondents indicated that they believe they would be able to get assistance with Bitcoin-related problems. Family, friends and significant others do not believe that these individuals should utilise Bitcoin at this stage. Finally, non-users do not perceive any benefit from utilising 
Bitcoin and do not intend to purchase or invest in the crypto currency. Whilst this study identified key determinants of Bitcoin usage, the following limitations are applicable.

\section{Conclusion, Limitations and Future Research}

This exploratory study was conducted to identify the determinants of Bitcoin adoption amongst end-user individuals in South Africa as well as to determine how Bitcoin is currently used by South Africans. For current users of Bitcoin, the results of the study revealed that all 5 constructs tested have a significant effect on behavioural intention to use Bitcoin. The current users view perceived usefulness as the most significant factor influencing their decision to use Bitcoin which correlates with findings by Abramova \& Bohme (2016) and Novendra \& Gunawan (2017). These users trust the Bitcoin network and its intermediaries but indicated that they do have concerns about potential cyber security breaches. The users indicated that it was easy for them to master transacting with Bitcoin which influences its continuing usage. Social influences, while influencing behavioural intention, was the least significant influencing factor. Perhaps this is due to Bitcoin only increasing in popularity with individuals and media over the past year in South Africa. Social influences could become an important factor in years to come. With regard to the current use of Bitcoin in South Africa, $66 \%$ of the respondents indicated that they are currently using the crypto currency as an investment in the crypto asset class while $34 \%$ reported that they are utilising Bitcoin as a speculative instrument. Currently, the primary reason that South African's currently utilise Bitcoin is for financial gain rather than as a digital currency to be used as a means of payment. Amongst non-users, lack of trust in the Bitcoin network and social influences were the most significant determinants thereby negatively impacting their decision to purchase, hold or use Bitcoin. The negative publicity about security breaches of various exchanges internationally as well as scams where South African's have fallen victim could be part of the reason these respondents do not trust the system or its various intermediaries.

Firstly, the findings in this study depend on the honesty of the respondents. Survey research is susceptible to participant bias, and it is known that individuals would agree more on socially desirable answers and disagree more towards socially undesirable ones. Secondly, as survey research was used to collect the data, the views of the participants will be those at the specific point in time of conducting the survey. The views of the greater population may well differ when measured over a longer time period and thus a longitudinal study should be conducted to determine if views change. This is particularly relevant for Bitcoin as the introduction of legislation and regulation regarding the trading or use of Bitcoin could change views over a period of time. Lastly, as the scope of the study is confined to end-users in South Africa, the findings cannot be generalised to other countries around the world. Continued research is needed in the area of crypto currency in South Africa. Some avenues that could be pursued include: investigating the potential effect of hedonic benefits associated with Bitcoin adoption; investigating obstacles faced by potential users in purchasing and using Bitcoin; conducting further research on individual's perceptions on the use of Bitcoin as a payment method in South Africa; investigating how Bitcoin profits are taxed by the tax authorities in other countries around the world and what mechanisms these authorities are utilising to identify such profits. It is hoped that this study provides insight into the factors influencing Bitcoin adoption in South Africa and serves as a catalyst for future research into crypto currency, adoption in South Africa.

\section{References}

Abramova, S. \& Bohme, R. (2016). Perceived Benefit and Risk as Multidimensional Determinants of Bitcoin Use: A quantitative exploratory study. Thirty-Seventh International Conference on Information Systems, (pp. 1-20).

Bamert, T., Decker, C., Elsen, L., Wattenhofer, R. \& Welten, S. (2013). Have a Snack, Pay with Bitcoins. 13th IEEE International Conference on Peer-to-Peer Computing, (pp. 1-5).

Bohr, J. \& Bashir, M. (2014). Who Uses Bitcoin? An exploration of the Bitcoin community. 12th Annual Conference on Privacy, Security and Trust (PST), (pp. 94-101).

Chau, P. Y. \& Hu, P. J. (2001). Information technology acceptance by individual professionals: a model comparison approach. Decision Sciences, 32(4), 699-719.

Cheng, T. C., Lam, D. Y. \& Yeung, A. C. (2006). Adoption of internet banking: An empirical study in Hong Kong. Decision Support Systems, 42(3), 1558-1572. 
Connolly, A. \& Kick, A. (2015). What Differentiates Early Organization Adopters of Bitcoin From NonAdopters? Twenty-first Americas Conference on Information Systems, (pp. 1-6).

Davis, F. D. (1989). Perceived usefulness, perceived ease of use and user acceptance of information technology. MIS Quarterly, 13(3), 319-340.

Edmunds, J. (2017). How South Africans use Bitcoin.

Folkinshteyn, D. \& Lennon, M. M. (2017). Braving Bitcoin: A technology acceptance model (Tam) analysis. Journal of Information Technology Case and Application Research, 18(4), 220-249.

Forza, C. (2002). Survey research in operations management: a process-based perspective. International Journal of Operations \& Production Management, 22(2), 152-194.

Fu, J. R., Farn, C. K. \& Chao, W. P. (2006). Acceptance of electronic tax filing: a study of taxpayer intentions. Information \& Management, 43(1), 109-126.

Gefen, D., Karahanna, E. \& Straub, D. W. (2003). Trust and TAM in online shopping: An integrated model. MIS Quarterly, 27(1), 51-90.

Gunawan, F. E. \& Novendra, R. (2017). An analysis of Bitcoin Acceptance in Indonesia. ComTech, 8(4), 241247.

Henry, C. S., Huynh, K. P. \& Nicholls, G. (2017). Bitcoin awareness and usage in Canada. Staff Analytical Note, Bank of Canada.

Hung, S. Y., Chang, C. M. \& Yu, T. J. (2006). Determinants of user acceptance of the e-government services: the case of online tax filing and payment system. Government Information Quarterly, 23(1), 97-122.

Kelso, C. (2017). South Africa's Bidorbuy Sees Sixfold Increase with Bitcoin.

Kumar, R. (2013). Bitcoin explained in layman's terms.

Leedy, P. D. \& Ormrod, J. E. (2010). Practical Research Planning and Design. (9, Ed.) Upper Saddle River, New Jersey: Pearson Education.

Li, X., Jiang, P., Chen, T., Luo, X. \& Wen, Q. (2017). A survey on the security of blockchain systems. Future Generation Computer Systems, 73(1), 1-13.

Liao, S., Shao, Y. P., Wang, H. \& Chen, A. (1999). The adoption of virtual banking: an empirical study. International Journal of Information Management, 19(1), 63-74.

Madeira, A. (2017). How does a Bitcoin ATM work or How to use a Bitcoin ATM.

McKane, J. (2018). South Africa's Cryptocurrency industy is booming.

MyBroadband. (2017). How many customers Luno has on its exchange.

Naidoo, P. (2017). South African's trading big volumes in Bitcoin.

Nakamoto, S. (2008). Bitcoin: A peer-to-peer electronic cash system. White Paper, 1-9.

Ngubeni, T. (2014). Takealot, Payfast join Bitcoin bandwagon.

Novendra, R. \& Gunawan, F. E. (2017). Analysis Of Technology Acceptance And Customer Trust In Bitcoin In Indonesia Using UTAUT Framework. Transactions on Internet and Information Systems, 1-18.

Pauw, C. (2017). Bitcoin futures, Explained.

Presthus, W. \& O'Malley, N. O. (2017). Motivations and barriers for End-User adoption of Bitcoin as Digital Currency. Procedia Computer Science, 121(1), 89-97.

Ram, A., Maroun, W. \& Garnett, R. (2016). Accounting for the Bitcoin: accountability, neoliberalism and a correspondence analysis. Meditari Accountancy Research, 24(1), 2-35.

Raviv, D. (2016). Is Bitcoin legal in South Africa?

Reid, F. \& Harrigan, M. (2013). An Analysis of Anonymity in the Bitcoin System. Security and Privacy in Social Networks, 197-223.

Rice, D. T. (2013). The Past and Future of Bitcoins in Worldwide Commerce. Business Law Today , 1-4.

Sas, C. \& Khairuddin, I. E. (2015). Exploring Trust in Bitcoin Technology: A Framework for HCI Research. OzCHI '15 Proceedings of the Annual Meeting of the Australian Special Interest Group for Computer Human Interaction, (pp. 338-342).

Schuh, S. \& Shy, O. (2015). U.S. consumers' adoption and use of Bitcoin and other virtual currencies. Working Paper, 1-48.

Sheppard, B. H., Hartwick, J. \& Warshaw, P. R. (1988). The Theory of Reasoned Action: A Meta-analysis of Past Research with Recommendations for Modifications and Future Research. Journal of Consumer Research, 15(3), 325-343.

Silinskyte, J. (2014). Understanding Bitcoin adoption: Unified Theory of Acceptance and Use of Technology (UTAUT) application. . Unpublished master's dissertation. Netherlands: University Leiden ICT in Business. 
Slabbert, A. (2017). Pay your traffic fines in bitcoin.

Sontakke, K. A. \& Ghaisas, A. (2017). Cryptocurrencies: A developing Asset class. International Journal of Business Insights \& Transformation, 10(2), 10-17.

Steyn, G. (2018). WATCH: SA's first business school now accepts bitcoin payments.

Szajna, B. (1996). Empirical evaluation of the revised technology acceptance model. Management Science, 42(1), 85-92.

Trautman, L. J. (2016). Is Disruptive Blockchain Technology the Future of Financial Services? The Consumer Finance Law Quarterly Report, pp. 232-242.

Tschorsch, F. \& Scheuermann, B. (2016). Bitcoin and Beyond: A Technical Survey on Decentralized Digital Currencies. IEEE Communications Surveys \& Tutorials, 18(3), 1-37.

Venkatesh, V. \& Davis, F. (2000). A theoretical extension of the technology acceptance model four longitudinal field studies. Management Science, 46(2), 186-204.

Venkatesh, V. \& Ramesh, V. (2006). Web and wireless site usability: Understanding differences and modelling use. MIS Quarterly, 30(1), 181-206.

Venkatesh, V., Morris, M. G., Davis, G. B. \& Davis , F. (2003). User acceptance of information technology: toward a unified view. MIS Quarterly, 27(3), 425-478.

Whigham, N. (2017). The fruitless search for Satoshi Nakamoto.

Williams, S. (2017). 6 Countries where bitcoin is banned.

Young, J. (2017). Japan Becomes Largest Bitcoin Market as Traders Leave China.

Zhao, W. (2017). Bitcoin Price Drops Below \$15k, Down 25\% from All-Time High. 